\title{
Behavior systems, associationism, and Pavlovian conditioning
}

\author{
WILLIAM TIMBERLAKE \\ Indiana University, Bloomington, Indiana
}

\begin{abstract}
Associative and behavior systems accounts of Pavlovian conditioning have different emphases. The traditional associative account has focused on the role of the unconditional stimulus (US) in strengthening stimulus associations according to a set of general laws. The behavior systems account has focused on the relation of conditional responding to the preorganized perceptual, motor, and motivational organization engaged by the US. Knowledge of a behavior system enables successful prediction of the form and ease of conditioning as a function of the type of conditional stimulus (CS), US, and the CS-US relation. At the same time, Pavlovian manipulations act as a window on how a behavior system works. Both associative and behavior systems accounts can be criticized as incomplete and idiosyncratic. A comprehensive account of Pavlovian conditioning could profit from their integration.
\end{abstract}

Laboratory-associationist and adaptive-evolutionary accounts of Pavlovian conditioning differ markedly in their focus. The former has emphasized the association between the conditional stimulus (CS) and the unconditional stimulus (US), and the role of the US in strengthening it (e.g., Hearst, 1988; Kimble, 1961; Mackintosh, 1974; Pavlov, 1927). Conditioning procedures have been refined and standardized to isolate the study of associations from the influence of instincts, nonassociative changes, and response-contingent reward (Hilgard \& Marquis, 1940; Kimble, 1961). More recent models have expanded the types of association and the role of context, multiple CSs, the CS-US contingency, and stimulus representations in determining behavior (e.g., Miller \& Matzel, 1988; Rescorla \& Holland, 1982). However, the focus has remained on associations among stimuli and the simple causal role of the US. Within this approach, behavior has been treated primarily as an index of the strength of associations.

In contrast, adaptive-evolutionary accounts of Pavlovian conditioning have emphasized behavior, especially the relation of the conditional response to the form and orientation of naturally occurring functional behavior and relevant underlying structure and processes (e.g., Davey, 1989; Fanselow \& Lester, 1988; Gardner \& Gardner, 1988; Holland, 1984; Hollis, 1982, 1990; Konorski, 1967; Rozin \& Schull, 1988; Timberlake, 1983b; Timberlake \& Lucas, 1989; Timberlake \& Silva, in press). In this approach, establishing the perceptual-motor organi-

Completion of this manuscript was facilitated by NIMH Grant 37892 and NSF Grant IBN 91 21647. The manuscript is based on a symposium presentation at the meetings of the American Psychological Association, Toronto, 1993. I am indebted to Cynthia Langley, Fran Silva, and Kathleen Silva for their comments. Please address correspondence to W. Timberlake, Department of Psychology, Indiana University, Bloomington, IN 47405 (e-mail: timberla@ucs.indiana.edu). zation and motivational processes underlying behavior is a critical step in understanding conditioning. Presentation of the US is viewed as engaging and constraining preorganized mechanisms underlying behavior, rather than as a simple, direct cause of conditional responding (Timberlake, 1993b).

The present paper outlines the behavior systems approach to Pavlovian conditioning - an approach that is related to the adaptive-evolutionary account and that attempts to combine structural and functional aspects of learning and behavior. The basic premise of the behavior systems approach is that the determinants of behavior have been organized by evolutionary selection pressure, development, and learning into functional systems, such as feeding, mating, parenting, and defense (Baerends, 1976, 1988; Fanselow, 1991; Fanselow \& Lester, 1988; Hogan, 1989; Scott, 1958; Timberlake, 1983a, 1983b; Timberlake \& Lucas, 1989; Tinbergen, 1951). The mechanisms and processes of a behavior system produce stimulus filtering and integration, timing and memory functions, motor components and programs, motivational states and hierarchies, and their neurophysiological substrates (Domjan, 1994; Fanselow, 1994; Hogan, 1994; Timberlake, 1993b; Timberlake \& Lucas, 1989). Behavior systems are species typical in that they are related to characteristic processes, structures, and environments. At the same time, individual differences are also expected on the basis of genetic, developmental, and experiential variation. Similarities and differences are also presumed to exist among species, based on the extent of common versus divergent phylogeny, selection pressures, and experience (Timberlake, 1993a).

The next section describes some distinguishing characteristics of the behavior systems approach to conditioning. I will then consider a specific behavior system-the feeding system of domesticated rats - and how it relates to the study of Pavlovian conditioning. I will conclude 
by considering the prospects for an integration of associative and behavior systems accounts of conditioning.

\section{BEHAVIOR SYSTEMS AND LEARNING}

The behavior systems approach is not primarily a theory of learning. It is, though, a theory that deals with the mechanisms and processes underlying functional behavior. Learning is embedded within a behavior system that inevitably influences the form, circumstances, speed, and maintenance of acquisition. The role of learning is assumed to have evolved in conjunction with the system and environment to facilitate the local fit of behavior and environment (Johnston, 1981; Nottebohm, 1972; Timberlake \& Lucas, 1989; Tinbergen, 1951). A behavior system provides the initial perceptual, motor, and motivational conditions and operating characteristics that organize and direct learning and in turn are reorganized and modified by learning. From these assumptions flow several general characteristics of a behavior systems approach.

\section{Learned Behavior is Complexly Caused}

In the traditional associative approach, learning is defined by and referenced to experimental paradigms, such as Pavlovian and operant conditioning. By defining learning in terms of the manipulations of the experimenter, the associative approach has encouraged the view that learning is caused in a simple, direct way by the presentation of the US (Timberlake, 1993b). For example, an important part of the carefully crafted distinction between operant and Pavlovian conditioning is based on procedural differences in how the reward is presented (Hilgard \& Marquis, 1940).

The behavior systems approach references learning to a functional context rather than to an experimental procedure. A critical attribute of a behavior system is that it produces strings of responses that lead toward or away from a particular stimulus or condition (Timberlake \& Silva, in press). These seemingly purposive strings are often probabilistic and fragmentary. Whether they actually achieve a particular outcome depends on the fit between the system and the environment, a fit that depends also on the effects of learning. The tendency to produce purposive strings so readily is presumed to result from evolutionary selection for responding that has increased the probability of survival and reproduction.

The behavior systems approach views the traditional experimental paradigms of learning research as procedures and environments that engage and constrain the functioning of a system in a way that evokes and supports learned behavior. Learning is not simply caused by presentation of a reinforcer, nor is it limited to a particular set of associations or a particular response. Learning modifies the functioning of a multilevel system of causal sequences. It occurs in forms ranging from local adaptation to a repeated stimulus through radical reorganization of the motivational structure of a system. Learning is produced by circumstances ranging from simple stimulus exposure to reciprocal response contingencies. It includes the conditioning of motivational states to external and internal stimuli; the alteration, integration, and recombination of motor programs; the differentiation and combination of stimulus classes; and the integration and sequential combination of perceptual, motor, and motivational determinants (Timberlake, in press; Timberlake \& Lucas, 1989).

It follows that the traditional procedural distinctions between Pavlovian and operant conditioning do not define critical differences in basic learning processes, but rather specify differences in how a system is engaged and measured (Gormezano \& Kehoe, 1975; Pear \& Eldridge, 1984). Because the underlying system is the same, the results of Pavlovian and operant conditioning should overlap as well. Thus, if food is presented to a hungry rat, the feeding system will influence the nature of learning whether the experimenter is using the procedures of operant conditioning, Pavlovian conditioning, habituation, or insight learning. For example, the use of a Pavlovian procedure to pair a moving stimulus with food and the use of an operant procedure to require the rat to contact the moving stimulus to obtain food have produced similar behavior (Timberlake, Wahl, \& King, 1982).

In short, in the behavior systems approach, specific learning paradigms can be viewed profitably as tools for investigating the nature and operation of the system and the role of learning in its expression. This is not to say that a particular learning paradigm cannot be used to investigate a specific form of learning. Just as a simple wiping reflex can be studied in a spinal frog, the conditioning of a simple salivary reflex can be studied by using Pavlovian procedures and a specially prepared and constrained dog. However, a similar difficulty is raised in both cases. As pointed out by many investigators, there is no simple spinal reflex in intact animals (Fearing, 1930; Sherrington, 1906). The spinal preparation only hints at how a reflex works in more typical circumstances. Similarly, there are no simple learned responses in animals that are free to move about the environment. As Domjan observes about his work on sexual conditioning (Domjan, 1994), a common US does not guarantee a uniform set of learning effects. Instead, learning will be expressed in a variety of forms that depend intimately on the circumstances.

\section{Learned Behavior is Specific and Constrained}

A primary goal of the associative tradition has been to establish general laws of learning not restricted to particular circumstances or species. Researchers have tried to ensure the generality of their work by using arbitrary stimuli and responses and artificial environments. At first glance, the behavior systems approach appears to take an opposite tack by establishing and using specific systems in studying learning. This latter approach stems from two beliefs: Initially, learning will be understood better by emphasizing its specificity; and ultimately, the specificity of initial analyses will allow better generalizations because of a more complete accounting of causal factors. 
In the behavior systems view, learning is constrained and determined by the nature of a specific system and the way it interacts with the environment. Classical comparative psychology established constraints on the ability of a species' sense organs to receive particular stimuli and their motor organization to produce particular responses (Maier \& Schneirla, 1935; Warden, Jenkins, \& Warner, 1935). A behavior system incorporates additional constraints based on sensory-motor integration, sequences of responding, the relation of motivation to stimulus and motor processing, and the overall regulation of the system.

Because many system constraints appear to have been selected on the basis of their contribution to survival and reproduction, it is not surprising that learned adaptive behavior is readily generated by a behavior system (Hollis, 1982). However, neither is it a surprise that a behavior system can contribute to the acquisition of maladaptive behavior as well. Both adaptive and maladaptive behavior are related to mechanisms and processes that in the animal's selection environment produce strings of responses likely to lead to an adaptive outcome (Timberlake \& Lucas, 1989). Which outcome will occur in a current circumstance will depend on the relation of that circumstance to the original selection environment, and on the potential contribution of prior learning.

Because we are dealing with specific mechanisms rather than a general associative process, manipulating circumstances ever so slightly may change adaptive into maladaptive behavior, and vice versa. For example, in the case of a pig trained to carry and deposit a token to obtain food (Breland \& Breland, 1961), a modest increase in the instrumental requirement changed efficient carrying into inefficient rooting. Apparently the resulting delay was sufficient to set the stage for the expression of the preorganized searching behavior of rooting.

\section{The Study of Learning Begins With the Study of Behavior}

The traditional associative approach expended a good deal of effort in isolating and precisely measuring learned responding in order to eliminate the effects of anthropomorphism and contamination from instinctive behavior, prior learning, or changes in motivation. Given that the initial behavior of animals in many learning environments looks ineffective and random (Thorndike, 1911), it is not surprising that investigators began to view learning as the means for constructing organized responding out of minimally organized or random behavior (Dashiell, 1937; Skinner, 1938; Timberlake, 1983b). The idea that learning constructed behavior almost from scratch also fit well with the belief of many Americans in equality and self-improvement through learning and hard work (Boring, 1968).

However, this conceptual allegiance to the power of learning was meliorated in practice by the care with which good experimenters designed their apparatus and procedures. In retrospect, learning researchers have been remarkably good at tuning their apparatus and procedures to produce a reasonable correspondence between environmentally defined responses and the processes and system structure of a US and a species (Moore \& Stuttard, 1979; Timberlake, 1990; Timberlake \& Lucas, 1989). Skinner $(1938,1956)$ presented an illuminating account of tuning his apparatus and procedures to establish the leverpress as an operant response. In the present view, tuning is a means of manipulating important components of the underlying behavior system without formally considering its characteristics. In this area, the behavior systems approach differs from the traditional associative account only in requiring the experimenter to explicitly acknowledge and substantiate the models of behavior that have been implicitly used all along.

A critical first step in studying learning from a behavior systems view is to establish the structures and processes of a system. The level of analysis must go beyond the traditional comparative approach of measuring sensory and motor capacities and include descriptions of preorganized perceptual-motor combinations and their relation to graded motivational states. Describing a system is accomplished by combining information about important stimuli, response components, and motivational states gained both from observations of freely occurring behavior and from the results of experimental work in the laboratory and the field. Freely behaving animals regularly produce purposive strings of responses. Close observation of animals in more restricted laboratory settings frequently reveals abbreviated versions of similar response strings.

Work on naturally occurring appetitive behavior is most useful when the observers have manipulated aspects of the circumstances to clarify the control of behavior. For example, Morris (1958) established the nature of motivational control underlying the courtship behavior of sticklebacks by examining the interruptibility of the courtship sequence at different points. Similarly, laboratory research is most useful when researchers tune their procedures and apparatus to create ties to natural appetitive behavior and report the topography of the resultant behavior (Timberlake \& Silva, 1994). For example, Galef's (1990) work on how rats exchange information about food locations provided a specific foraging context and examined the relation of the form of the rat's behavior to its function in transmitting the information.

A behavior systems approach to learning also encourages and even requires consideration of issues of development, ecology, and evolution, as well as the neurophysiological and genetic substrates underlying behavior. The work of Fanselow and his associates (Fanselow, 1991, 1994; Fanselow \& Lester, 1988) shows the advantages of establishing relations between the behavioral expression of a defensive system in rats and its neurophysiological underpinnings. The work of Hogan (1989, 1994) has shown how a behavior systems approach can help us to understand the process of development of pecking for food in chicks or dustbathing in jungle fowl.

In sum, the behavior systems approach produces learned behavior based on the interaction of the mechanisms and processes of the system with the constraints of the envi- 
ronment. Learned responding is not caused in a simple way by the procedures of the experimenter; it is a complex reaction of the system to those procedures. The results of a particular learning manipulation aid in the ultimate process of generalization to the extent that they reveal the specificity of underlying mechanisms and processes. The more clearly the experimenter can specify how learning fits into a behavior system, the clearer will be the extent of the possible generalizations to other circumstances and the ties to other levels of analysis.

\section{AN EXAMPLE: PAVLOVIAN CONDITIONING IN THE FEEDING SYSTEM OF RATS}

For several years my laboratory has studied how the feeding system of rats contributes to and is modified by Pavlovian learning procedures. We have found it useful to represent the feeding system of the rat as a hierarchy of motivational states and perceptual-motor units, similar to the systems proposed by classical ethologists to account for the behavior related to reproduction in fish (e.g., Baerends, 1976; Tinbergen, 1951). Our feeding system (shown in Figure 1) represents a set of hypotheses and assumptions based on observations and experiments of ours and of many other researchers (e.g., Barnett, 1975; Calhoun, 1962; Ewer, 1971; Galef, 1990; Steininger, 1950; Telle, 1966). The feeding system is necessarily incomplete and provisional, but laying out a concrete system allows predictions to be made and tested and any necessary corrections to be incorporated into the same basic framework.
There are five hypothesized levels: system, subsystem, mode, module, and action pattern. The system level (not shown in Figure 1) refers to the tendency for behavior and stimulus processing to be organized around biologically important functions, such as reproduction or feeding. Subsystems combine a subset of stimulus sensitivities, response components, and motivational states into strategies for advancing the function of the overall system. For example, the predatory subsystem in the rat involves sensitivity to moving stimuli and increased likelihood of chase and capture responses.

Modes are motivational substates underlying the sequential and temporal organization of appetitive strings of responses. Modes can be distinguished roughly on the basis of their proximity to food. Thus, a general search mode, shown at the top middle right of Figure 1, is related to stimuli and behaviors concerned with finding food when food is not imminent, while a focal search mode is related to stimuli and behavior dealing with imminent food. When food is present, the animal enters a handlingconsuming mode, in which action patterns related to handling and feeding occur. Modules represent groupings of stimulus filters, mechanisms of sensory integration, and motor components and programs. For example, in a predatory species, a moving object stimulates perceptual filters sensitive to movement that are related to responses such as chasing and capturing. The four levels of control specified above combine to select and coordinate individual responses, termed action patterns.

Pavlovian and operant conditioning procedures can be used to explore the nature of the behavior system and

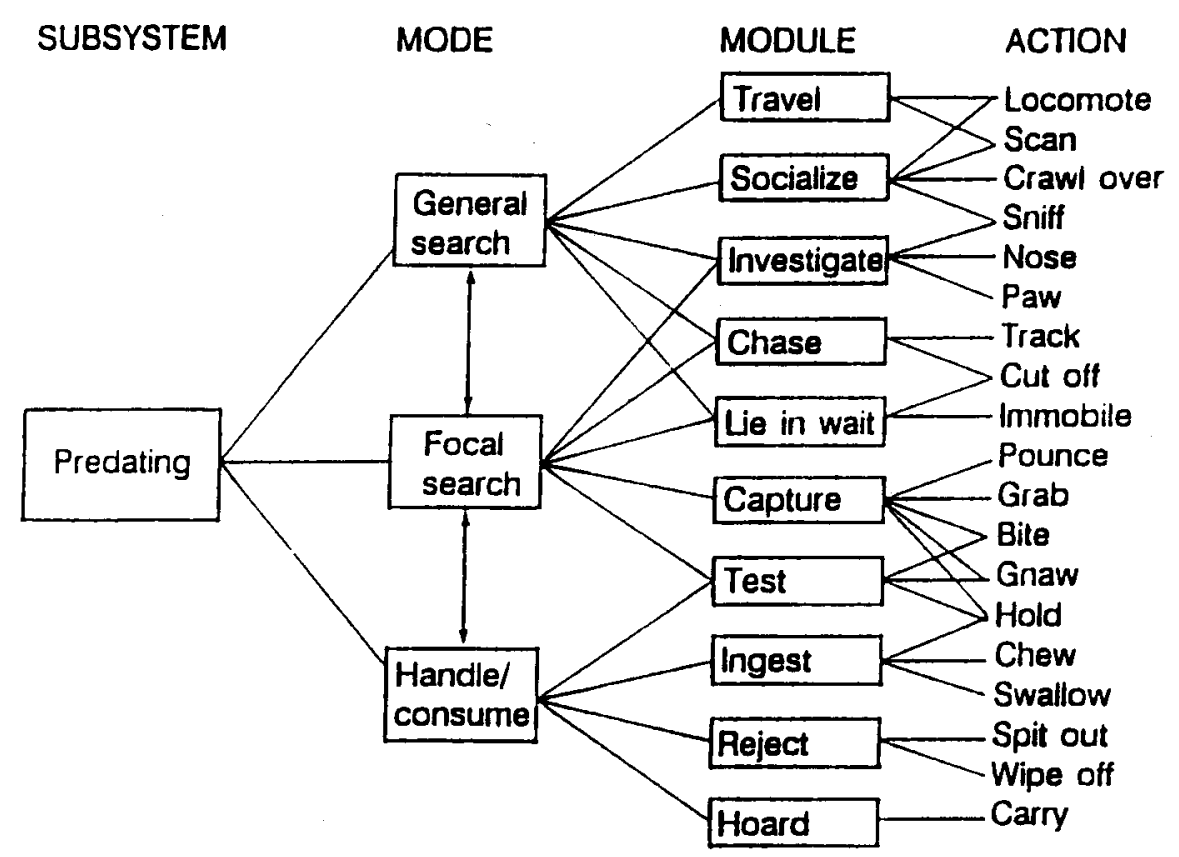

Figure 1. A representation of the predatory subsystem of the feeding system of a rat. Subsystems combine stimulus sensitivities, response components, and motivational states into strategies for dealing with subsets of the function of the overall system. Modes are motivational substates underlying the sequential and temporal organization of appetitive strings of responses. Modules represent groupings of stimulus filters, characteristic processing mechanisms, and particular motor programs. Finally, action patterns refer to the actual responses. 
the role of learning in its expression. Pavlovian procedures allow the experimenter to manipulate the characteristics of a CS and its relation to a US, thereby exploring the nature of specific perceptual-motor modules and motivational states. Because the experimenter does not specify the conditional response (CR), it is free to reflect motor organization related to the system, the perceptual qualities of the CS, and its temporal and spatial relation to the US. In operant conditioning, the experimenter can create a juxtaposition between food delivery and the form and/or frequency of a particular response, thereby examining the organization and flexibility of the system.

Both conditioning procedures also can be used to test predictions based on a specific behavior system. For example, using Pavlovian procedures, the experimenter can manipulate the nature of the CS, the US, the temporalspatial aspects of the CS-US relation, and the species to test predictions about responding. Such data have been reviewed previously by Timberlake, (1983b, 1990, $1993 \mathrm{~b}$, in press), Timberlake and Lucas (1989), and Timberlake and Silva (1994, in press). Below, I briefly indicate evidence for the effects of feeding system modules and modes on Pavlovian conditioning.

\section{Feeding System Modules in Conditioning}

The modules shown in the right half of Figure 1 refer to perceptual-motor units that combine stimulus filters, motor components, and linkages among them. When a cue passes a filter, it increases the probability of functional behavior in a hungry rat. In the case of highly preorganized modules, stimulus filters are often narrowly tuned for specific sensory qualities and produce predictable response forms. In the case of less organized modules, the stimulus filters may be broadly tuned, perhaps sensitive only to the physical and temporal proximity of the stimulus to food. Initial ties to responding may also be relatively diffuse. We will briefly consider examples reflecting both sets of characteristics.

Highly preorganized modules. The predatory capture module in rats is a good example of a perceptual-motor module with a narrowly tuned filter connected to wellorganized response components. There is a strong link between a small moving stimulus and motor patterns related to chasing and attempting to capture and subdue the stimulus. For example, simply rolling a ball bearing past an active rat produces rapid approach and contact with the bearing about $25 \%$ of the time, with responses that resemble how a rat deals with moving insects. Another example of a preorganized perceptual-motor unit is the social module. Presenting another rat as a stimulus will produce frequent approach and interaction with the stimulus rat, including sniffing the anogenital area, grooming, and crawling over. Following either a ball bearing or a rat with food produces an increase in the frequency and complexity of interaction with the stimulus. In the case of the ball bearing, the rats began to dig the bearing out of the entry hole, carry it to the end of the cage, and gnaw, drop, and repeatedly retrieve it (Timberlake et al., 1981). Rats presented with food following ac- cess to a stimulus rat increase anticipatory approach to the location of the rat and sniffing of the mouth and head (Timberlake, 1983b; Timberlake \& Grant, 1975).

Some highly preorganized modules do not even require the presence of food to increase integration and performance. Simple repeated exposure to relevant stimulus conditions is sufficient. For example, food-deprived rats rapidly begin to efficiently search a radial arm maze in the absence of any food on the maze (Timberlake \& White, 1990). Rats also run straight alleys and more complex choice mazes efficiently in the absence of food (Brant \& Kavanau, 1965; Timberlake, 1983a).

It is important to realize, though, that increases in responding are not an inevitable outcome of the presence of a highly preorganized module. Some modules do not increase responding even (or especially) when followed immediately and reliably by food. This result may be due to a weak relation between a particular module and the feeding system and/or a strong relation between the module and a conflicting system. For example, adult rats readily approach and interact with a 20 - to 30 -day-old juvenile rat, thereby providing evidence for a perceptualmotor module involving social interaction with juveniles. However, in contrast to the increase in interaction with adult rats that are paired with food, pairing a juvenile with food does not affect the level of interaction (Timberlake, 1983b). Presumably this result differs from that for the adults because approaching juveniles is not included in the adult feeding system. This possibility makes sense if we recall that juveniles are still dependent on adults for information about the location and safety of diet items (Galef, 1990).

In a similar experiment, male hamsters were used to signal food for another hamster. Although male hamsters apparently have a perceptual-motor module supporting social interaction with other males, there are reasons to predict that this module should not be an important part of the hamster feeding system. Hamsters are not social feeders; they tend to be solitary, except in reproduction. Thus, pairing a hamster with food should at best have no effect on and might produce a decrease in social interaction because of the possibility of food competition. In a test of this prediction, pairing a hamster with food actually decreased approach, which recovered to baseline levels when the food was removed (Timberlake, 1983b).

Less preorganized modules. In numerous laboratory situations, there has been little evidence of striking perceptual-motor organization prior to conditioning. In many cases, only orienting responses are shown to the CS when it is presented alone (Holland, 1980). However, when the same CS is paired with food, well-formed responses rapidly emerge and in fact may resist the effects of negative response contingencies that omit food if the animal responds. For example, pigeons rarely peck illuminated keys, but readily peck if the lighted key predicts imminent food (Hearst \& Jenkins, 1974); the pigeons persist in pecking even if it costs them feeding opportunities. Other bird species also engage illuminated keys 
paired with food by using motor patterns similar to those used in foraging (Kamil \& Mauldin, 1988). Also, blue gourami aggressively move to the location where a rival will appear when a predictive light appears (Hollis, 1990), while quail will move rapidly to the location where they will be able to see a receptive female (Domjan, 1994). Obviously, the absence of significant unconditional expression of responses to the CS prior to training does not mean that no module exists. Rather, it appears that a stimulus pairing or a response contingency is necessary to produce the level of motivation, perceptual tuning, and/or stimulus-response integration necessary for reliable expression of the module.

It might be argued that operant conditioning effects are less likely than Pavlovian effects to be based on preorganized perceptual-motor modules. But this is not necessarily the case. For example, rolling a ball bearing predicting food past a variety of rodent species has failed to produce the high level of interaction readily shown by rats. However, requiring that the animal contact the ball bearing in order to obtain food has revealed a variety of species-typical patterns of contact that resemble how the species interacts with crickets (Timberlake \& Washburne, 1989). For example, the California mouse (Peromyscus californicus) contacts the bearing with lunge-bites, paws outstretched, and mouth open, while spiny mice (Acomys caharinus) run beside the bearing, biting at it intermittently.

Even the traditional instrumental responses of keypecking in pigeons and maze running in rats appear to require some form of preorganization to account for their rapid emergence under Pavlovian contingencies and/or simple exposure. But surely leverpressing is assembled through the arbitrary strengthening action of reinforcement? Perhaps not. Skinner (1938) pointed out that with a sufficiently long trial there was an operant baseline level of leverpressing. Stokes and Balsam (1991) have documented that the components of reinforced leverpressing exist in the initial exploratory behavior of the rat.

There is, though, one area of obvious arbitrary associations. A counterbalanced discrimination experiment requires that each stimulus is both rewarded and unrewarded, depending on the subgroup of animals. But this fact is not evidence against perceptual-motor modules, only evidence that they can be tuned by means of stimulus and/or response contingencies related to access to food.

In short, learned behavior is surprisingly preorganized. When a rat enters a situation involving food, it "brings with it" structures and processes relevant to foraging and learning about the location and characteristics of food. Preorganized is not a code word for "genetic"; it is simply a statement that in subjects of a particular age exposed to a particular range of environments, there exist certain modules, modes, and systems. Ethologists, such as Kruijt (1964), and psychologists such as Bolles and Woods (1964) and Gottlieb (1976) have documented the emergence of explicit sensory and motor organization during development.

Hogan $(1984,1989)$ has gone further in studying the role of learning in the development of deprivation- related pecking in young chicks (see Hogan, 1994, Figure 6). Apparently, pecking is unrelated to deprivation until the chick has eaten its first meal. This seemed intuitively reasonable from several standpoints until Hogan clarified the mechanisms involved. The connection between pecking and deprivation is not limited to the normal ingestion of food, but can be triggered by allowing the chick to peck grain that cannot be ingested (because it is glued to the substrate) and then force-feeding the chick the nonnutritive substance of sawdust. Such a roundabout technique clarifies that the feeding system has evolved to depend on learning for its development, but in a way that is based on system-specific rather than general mechanisms.

\section{The Contribution of Modes}

The modules in Figure 1 can be viewed as candidates for different sequences of behavior (moving top to bottom). The sequence that occurs in a particular circumstance will be determined by the way in which these possible links interact with the environmental stimuli and constraints. Figure $2 \mathrm{~A}$ shows a sequence of modules that could readily occur in the case of a hungry rat searching for food (Timberlake \& Silva, in press). Beginning with the modules at the top of the figure, the rat engages in locomotor search in response to general environmental stimuli until it encounters a distal moving stimulus, whereupon it gives chase until it captures it. The rat then tests the prey item by biting and turning it until it discovers edible portions, which it chews and swallows.

In addition to showing how purposive strings of responses can emerge from interaction with the environment, Figure $2 \mathrm{~A}$ also indicates that a purposive string is supported by a sequence of motivational modes (the leftmost column). A typical sequence of modes related to feeding begins with general search, moves to focal search, to handling-consuming, and back to (postfood) focal search, and then returns either to handling-consuming or general search, depending on the immediate probability of more food items. Evoking particular modes and their transitions is initially dependent on the unconditional priming qualities of particular cues. For example, presenting a distal moving stimulus to a hungry rat should have two effects: It should increase the strength of the general search state and elicit modules related to locomotor search and chase.

Following several instances of successful predation under similar stimulus conditions (essentially learning trials), search modes should come under the control of other temporal and spatial cues in the environment to the extent that they are reliable predictors of food. For example, examination of Figure $2 \mathrm{~A}$ suggests that the chase module (controlling responses of tracking and running after a moving stimulus) is most strongly related to general and early focal search modes, whereas the test module (controlling holding and gnawing) is more strongly related to later focal search and handling-consuming modes. In addition, we have data suggesting that with sufficient experience in a particular situation, the focal 
search mode is extended in time and space, whereas the handling-consuming mode becomes more confined to cues highly correlated with the delivery of food.

By combining the assumption that modes depend on spatial and temporal proximity to food (as well as particular stimuli and previous training), it is possible to make testable predictions about the form and control of learned responding under a variety of Pavlovian manipulations. For example, in the traditional associative account of the effects of the CS-US interval on responding, conditional responding peaks at brief intervals and decreases rapidly as the interval increases in size. This prediction follows from the notion that the associative strength linking two stimuli is a largely decreasing function of the time interval between them.

The behavior systems approach leads to a different prediction: the shortest CS-US intervals should best condition a handling-consuming mode and related responses; a slightly longer CS-US interval should better condition a focal search mode and related responses; and an even longer CS-US interval should best condition a more general search mode and related responses. The behavior systems approach may help explain several empirical characteristics of Pavlovian conditioning. In the case of a food US, responses related to the handlingconsuming mode, such as salivation, and to extreme focal search behavior, such as nosing or digging in the food tray, should show peak conditioned responding close to the onset of the US. In contrast, responses related to a more distant focal search or a general search mode, such as manipulating a lever or approaching a rat, should show timing functions with peaks occurring when the animal is more distant from food. The same should be true of physiological indicators of more general arousal, such as heart rate acceleration (Schneiderman, 1972).

I offer four examples in which presentation of the same CS produces different forms of responding as a function of the CS-US interval. These effects appear to relate to the

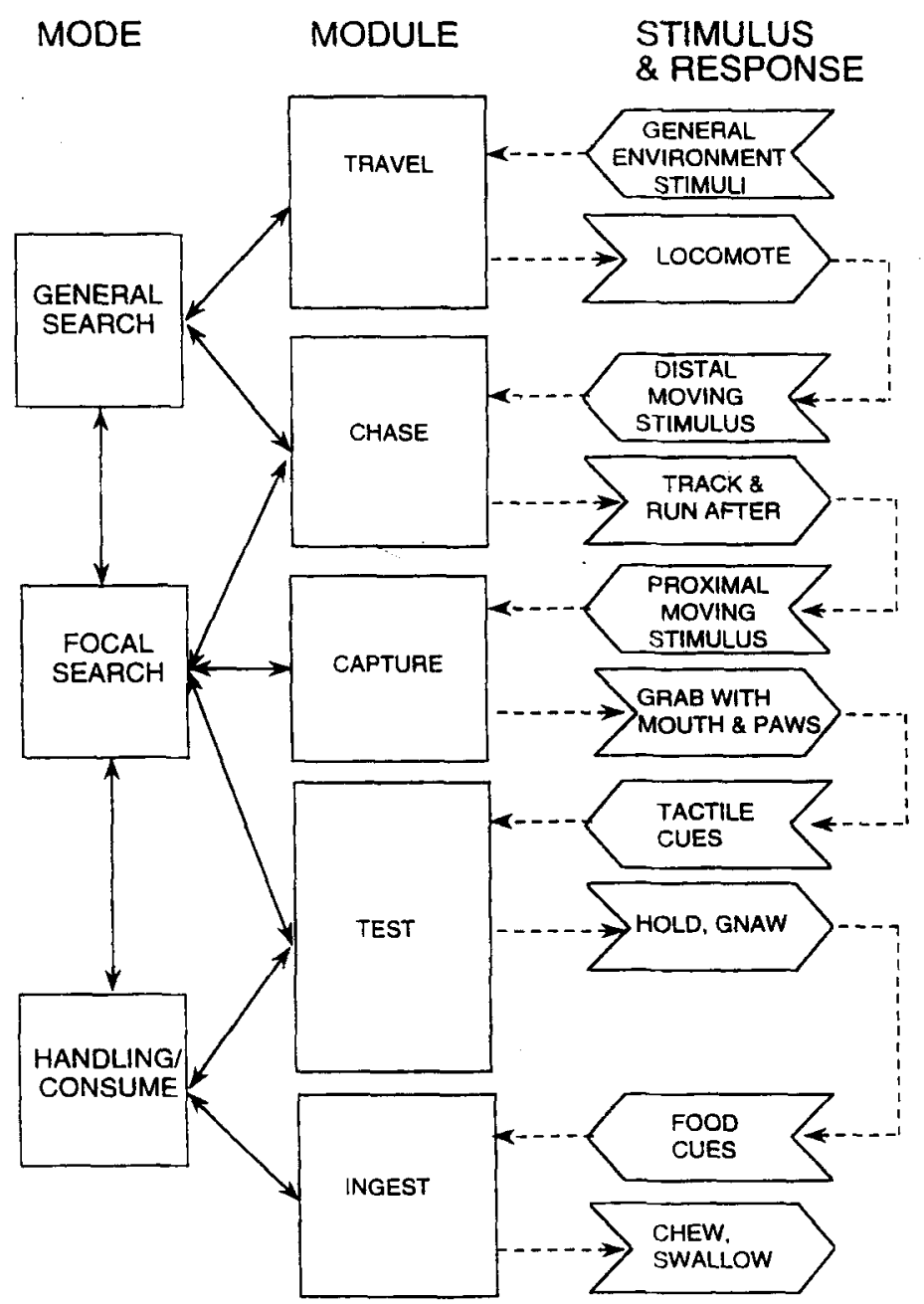

Figure 2A. Inputs and outputs to selected modules and their related modes taken from the feeding system of the rat shown in Figure 1. The dotted lines, proceeding from the top to the bottom of the figure, show how a predatory string of responses can easily emerge from a behavior system in the presence of appropriate stimulus conditions. 


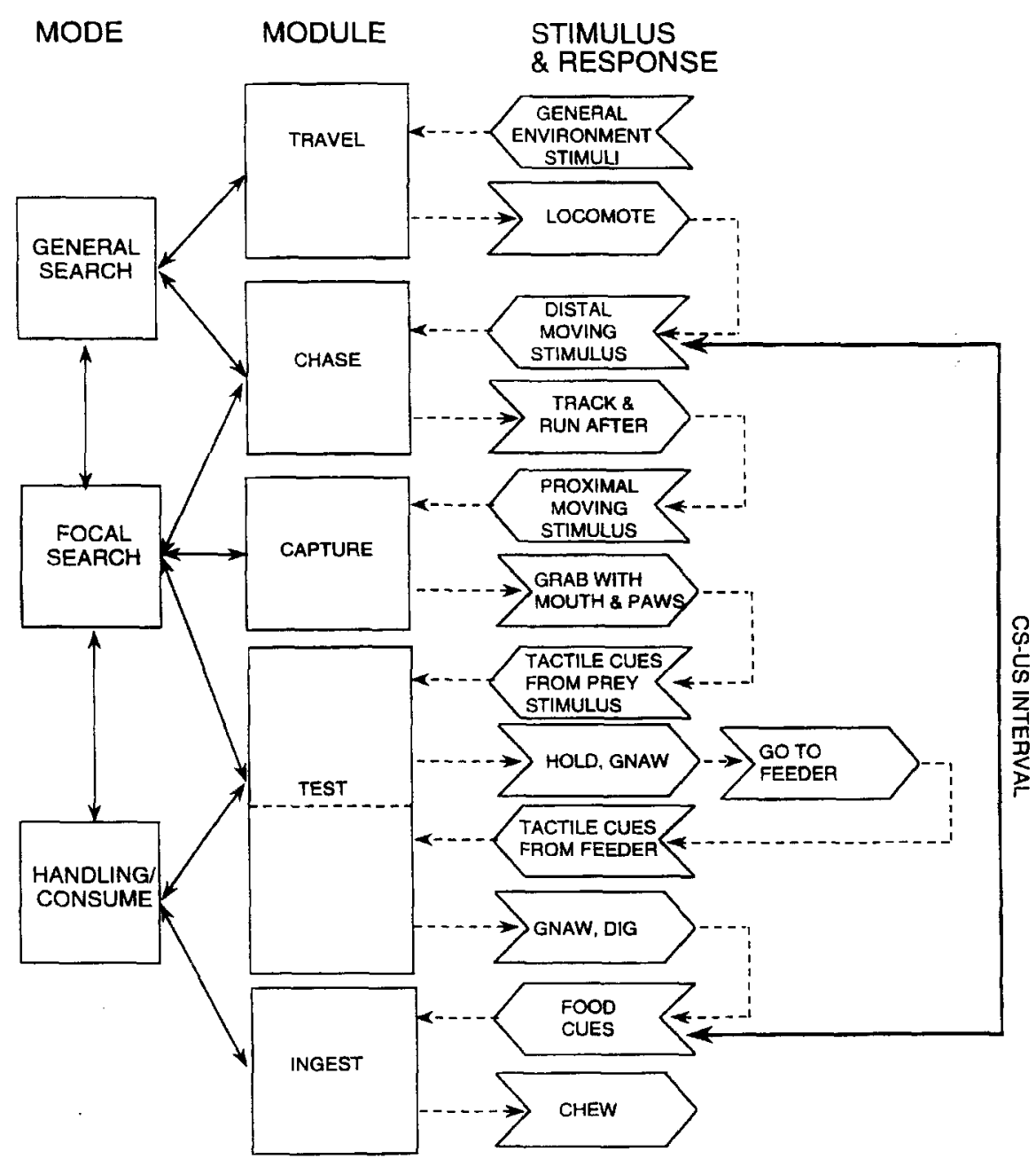

Figure 2B. Inputs and outputs to the modules and modes of Figure $2 \mathrm{~A}$ when an artificial moving stimulus (a ball bearing) is used rather than a naturally occurring prey item and a moderate CS-US interval is imposed between the delivery of the bearing and food. A major change from the appetitive string shown in Figure $2 \mathrm{~A}$ is required because the animal cannot complete the usual string of responses by opening and eating the bearing, so the rat must make a transition to directing focal search and handling behavior to the food tray.

conditioning of different search modes and responses related to them. The first instance concerns manipulation of the CS-US interval between presentation of a rolling ball bearing and food. The CS intervals were 2.6 and $7.6 \mathrm{sec}$. Figure 2B shows the potential modes and responses related to a moving stimulus predicting food. There are two major differences between Figures $2 \mathrm{~B}$ and $2 \mathrm{~A}$. The first is that when the CS is a ball bearing rather than an insect, the animal must at some point give up holding and gnawing the bearing and direct its testing and handling behavior toward the feeder. As might be expected, rats do not make this transition gracefully. It is like switching prey items when you are about to eat. In fact, many rats figure out ways to combine holding the bearing and going to the feeder. For example, several rats placed the ball bearing in the feeder, picked up the pellet, and then picked up the bearing again and held and gnawed it further.

The second difference from Figure $2 \mathrm{~A}$ is the dark vertical line on the right side of Figure $2 \mathrm{~B}$ that shows how the temporal relation between the bearing and food delivery appears to interact with the system when the CS-US interval is $7.6 \mathrm{sec}$ or more. This CS-US interval conditions more general and some focal search modes. The rat treats the ball bearing as a prey item, chasing, seizing, carrying, and gnawing it before eventually giving it up in favor of going to the food tray. A similar line on the right side of Figure $2 \mathrm{C}$ shows how a CS-US interval of $2.6 \mathrm{sec}$ interacts with the system. This shorter CS-US interval conditions extreme focal search and handling-consuming modes. The moving stimulus is used as a cue to approach and dig and burrow in the food tray. Data supporting this account can be found in Timberlake et al. (1982).

Domjan (1994) has applied a similar approach to the study of the effects of the CS-US interval on the conditioning of male Japanese quail to a light predicting visual access to a receptive female quail. Akins, Domjan, and Gutierrez (1994) compared the delay conditioning effects of a 30-sec CS with those of a 1,200-sec CS. The 


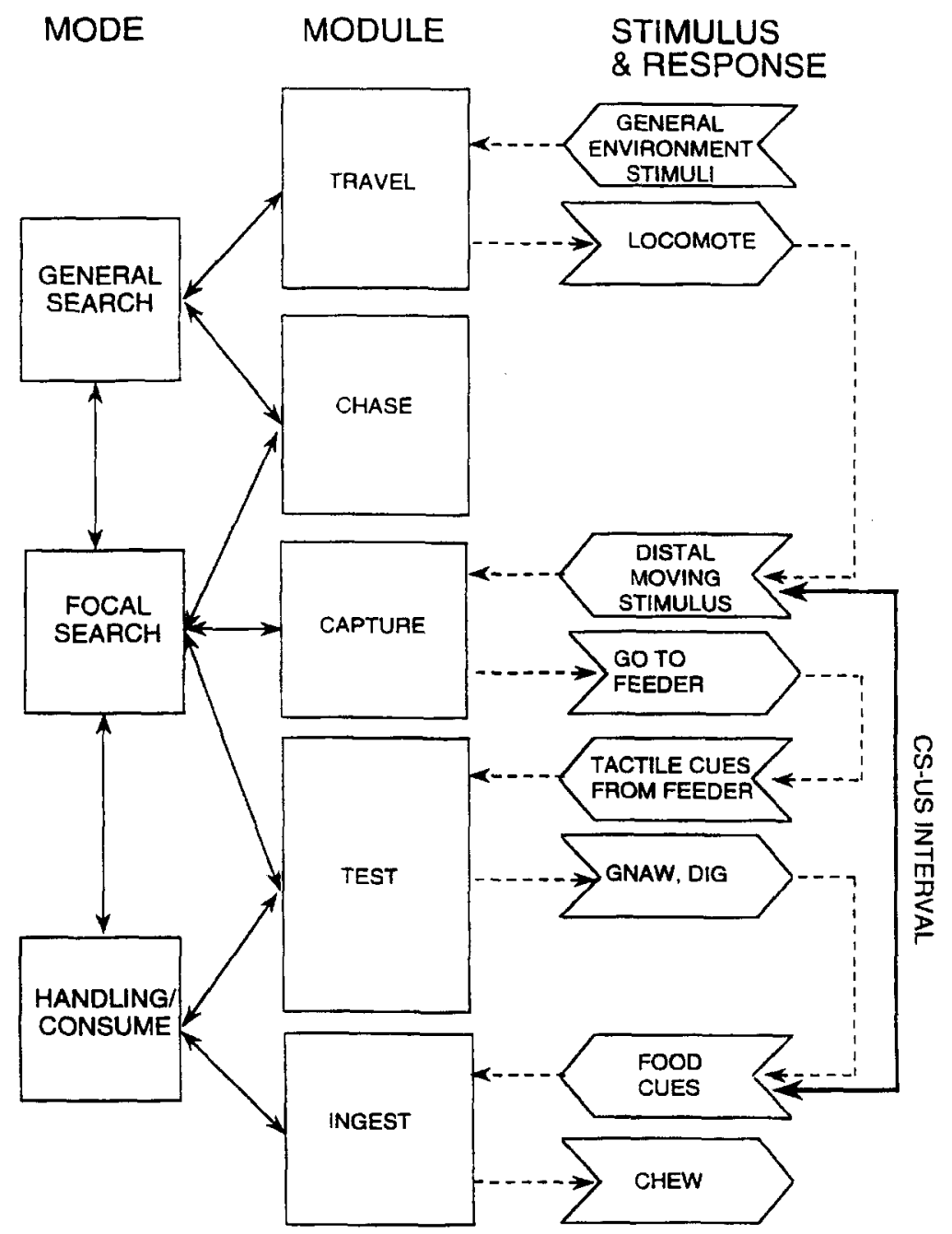

Figure 2C. Inputs and outputs to the modules and modes of Figure $2 \mathrm{~A}$ when an artificial moving stimulus (a ball bearing) is used rather than a naturally occurring prey item and a short CS-US interval is imposed between the delivery of the bearing and food. The shorter CS-US interval is assumed to condition the focal search and handling modes, thereby supporting going to the food tray rather than interacting with the bearing.

$30-$ sec CS strongly conditioned approach to the area in which visual access to the female was presented. The $1,200-\mathrm{sec}$ CS did not increase approach to the vicinity of visual access, suggesting an absence of conditioning. However, the 1,200-sec CS markedly increased locomotor activity - just what would be expected if a general instead of a focal search mode were conditioned by the 1,200 -sec CS-US interval.

An example that relates modes to a specific neurophysiological substrate is found in the work of Fanselow and his associates (Fanselow, 1991, 1994; Fanselow \& Lester, 1988). Fanselow has identified a temporal dimension of predatory imminence related to the occurrence of an aversive event (shock). By manipulating the CS-US interval between the predictive stimulus and shock, he has shown that this temporal dimension can be divided into three modes related to the negative event. Each mode is associated with a particular set of activat- ing stimuli and consequent behaviors; two modes are also related to particular anatomical structures in the brain. A preencounter mode is activated by receiving stimuli with some predatory potential; it produces caution and avoidance. A postencounter mode is activated by the detection of a predator and produces freezing, potentiated startle, and opiate analgesia. This mode is related to the ventral periaqueductal gray and the amygdala. A circastrike mode is activated when contact with the predator is present or immediate and involves attack and defensive fighting, escape, displays, and nonopiate analgesia. This mode is related to the dorsolateral periaqueductal gray and the superior colliculus (see Fanselow, this volume).

Finally, Matthews and Lerer (1987) have provided strong evidence that modes both support response strings and can be conditioned to external stimuli. In their experiment, hungry pigeons were presented with grain each $30 \mathrm{sec}$. During the interfood interval, a keylight went 
from dim to very bright, so that the first $10 \mathrm{sec}$ were dim, the second $10 \mathrm{sec}$ averaged a medium intensity, and the third $10 \mathrm{sec}$ averaged very bright. This procedure produced a consistent ordering of responses. The pigeons showed circling away from the hopper during the first 10 sec interval, wall-directed behavior during the second $10 \mathrm{sec}$, and increased pecking during the final $10 \mathrm{sec}$.

In the behavior systems view, presenting food on a regular basis conditioned a sequence of modes beginning (after postfood focal search) with a general search mode, then a focal search mode, and finally a handlingconsuming mode. The predictable changes in the intensity of keylight illumination should come to control the underlying modes. Compared with what we know about a pigeon's feeding system, the behavior during the first $10 \mathrm{sec}$ resembled circling components of general ground foraging; the behavior during the second $10 \mathrm{sec}$ may have related to food begging; the behavior during the last $10 \mathrm{sec}$ resembled response related to food acquisition and handling, such as procuring or breaking open seeds.

These data do not require a behavior systems analysis if one argues that the pigeons somehow acquired a learned response chain in which the results of each response served as a stimulus for producing the next response. However, Matthews and Lerer (1987) ran a series of test conditions which cast doubt on the response-chain account. In one test procedure, the change in illumination of the keylight was reversed, beginning as a bright light and growing successively dimmer. The pigeons' behavior reversed to coincide with the lighting changes. They pecked predominately during the first $10 \mathrm{sec}$, continued with wall-directed behavior in the second $10 \mathrm{sec}$, and ended with circling behavior. These data show easy reorganization of the order of responding, and indicate that the responses expressed are supported by motivational modes conditioned to different levels of illumination.

In short, conditioned search modes appear to be an important determinant of sequences of responding. Other things equal, the results of manipulating the CS-US interval in Pavlovian conditioning can be predicted and understood as a product of the temporal proximity of the CS and food. Different responses should peak at predictable CS-US intervals determined by which mode the response is most related to. Also, the same stimulus should be able to condition different responses, again depending upon the CS-US interval. Short CS-US intervals are more likely to produce focal search and handling-consuming related responses. Long CSs are most likely to produce responses related to a general search mode. Other dimensions of proximity between the CS and the US, such as spatial or contingency relations, may also be understandable in terms of the conditioning of modes and their related responses. For example, the more reliable a contingency, the more likely a handlingconsuming mode will be strongly conditioned, whereas the less reliable, the more likely a general search mode will be relatively stronger.

\section{PROSPECTS FOR INTEGRATION}

It is important to emphasize that associative and functional accounts are neither mutually exclusive nor necessarily contradictory (Timberlake, 1993b). They are, though, different. Over the course of this paper, I have highlighted several differences in conceptual analysis and emphasis between associative and behavior systems accounts of Pavlovian conditioning. These differences extend even to the level of data-taking and focus. The behavior systems approach views response topography as primary data and inference of potential ecological function as a critical step in analyzing learning. The associative approach focuses on the rate or latency of a simple environmentally defined response that is assumed to index the strength of simple associations that are based on the general laws of learning (Timberlake \& Silva, 1994). The lack of overlap in these accounts argues that the two approaches could profitably be combined to produce a more complete account. However, many factors mitigate against such an integration (Jenkins, 1979); they include the tradition of critical tests, perceived drawbacks to the behavior systems approach, and the perceived sufficiency of the associative approach.

\section{The Critical Test Tradition}

One stumbling block to integration is the time-honored tradition of the critical test. A critical test involves the careful contrast of alternative hypotheses in a sort of scientific shoot-out, at the end of which only one view is left standing (Platt, 1964). Because the associative and behavior systems approaches can be used to account for the results of similar manipulations, it is inevitable that their predictions will be pitted against each other. Much can be gained by contrasting alternative hypotheses in a single experiment. The process often leads to a more careful consideration and clearer specification of how a theory is constructed and applied. For example, I think it would be enlightening to determine whether behavior in the first half of an interfood interval reflects inhibition, as the associative view suggests, or general search, as suggested by the behavior systems approach.

It seems equally as enlightening, though, to focus on potential areas of agreement and complementarity. For example, inhibition of focal search behaviors may not be incompatible with excitation of general search behaviors. It could be that general search modes compete with focal search modes for conditioning and/or expression. I would like to see a new tradition of critical tests that identified potential commonalities and complementary qualities as well as important differences. The history of learning research contains numerous examples in which one viewpoint was dispatched by a critical experiment, only to return years later, its warts still preserved by inactivity, summoned as the shortcomings of the initially victorious view cumulated (e.g., Wasserman, 1993). In at least some cases, it would have been more efficient in the long run to combine rather than eliminate alternative views. 


\section{Perceived Drawbacks to the Behavior Systems Approach}

Reviewers of this set of papers expressed several considerations about the behavior systems approach. I have grouped them as they relate to issues of potential integration.

Behavior systems are too complex. A common objection to the behavior systems approach is its apparent complexity. The sheer number of initial assumptions contrasts unfavorably with the apparent sleek economy of the traditional concept that behavior is based on the reinforcement of simple connections. I believe, though, that this argument misses the mark. The source of the contrast is not so much the complexity of a behavior system, but the failure of the traditional associative account to acknowledge and make clear the full set of assumptions and requirements necessary for its testing and application. To establish a rat feeding system is simply to make explicit what experimenters deal with in tuning their apparatus, procedures, and measures in order to test hypotheses about apparently simple associative mechanisms (Timberlake 1993a, 1993b; Timberlake \& Silva, in press). I believe that it is better in the long run to state and test one's model of the animal than simply to incorporate it into the apparatus and procedure.

The behavior systems approach is actually quite simple: Determine the operating characteristics of a system, hypothesize how they relate to learning, and use manipulations to explore the multiple causal sequences present. The complexity of the behavior systems approach lies at the level of establishing the characteristics of the system. But that is where it should be. In the behavior systems approach, tuning has conceptual meaning and direction and its results are preserved. The overt simplicity of the associative account continues to disappear as researchers carefully investigate mechanisms of attention and other cognitive processes involved in standard learning paradigms, such as serial conditioning (Kehoe, 1982). Adding a behavior systems approach may provide a larger framework for combining issues of attention and cognition with motivation, evolution, and neurophysiology.

Behavior systems are idiosyncratic. It has been suggested that the behavior systems approach is idiosyncratic, both in terms of a lack of generality across systems and species, and because investigators may propose different versions or predictions of a system. Although each behavior system may be specific to a particular species and function, it is the kind of specificity that appears to encourage several dimensions of generalization, thereby moving comparative research beyond the stage of cataloguing. A lot of the specificity is in the particular perceptual motor modules that constitute a particular system. At least qualitatively, motivational modes appear as relevant to courtship in quail (Domjan, 1994) and to defensive behavior in rats (Fanselow, 1994) as they do to foraging in rats. I would not be surprised if similar modes were relevant to feeding in Hogan's chicks as well (Hogan, 1984). The point is that generalizations are likely to be based on similar selection pressures and homologous perceptual and motor characteristics. This sort of generalization has been too often missing from the history of comparative research on learning.

It has also been suggested that the behavior systems approach is idiosyncratic in that it can only be used for prediction by the person who has outlined the system (e.g., Mazur, 1990). To anyone unfamiliar with a behavior system, the predictions may appear to emerge unexpectedly and therefore idiosyncratically. However, a behavior system is a generally accessible set of hypotheses that is generated by combinations of inductive and deductive processes (see Domjan, 1994; Timberlake, 1983b). The representation of the rat's feeding system shown in Figure 1 was created over several years, to summarize and integrate the data of a dozen or more investigators. It is a theory of the structures and processes and their relation to a rat's feeding behavior. The boxes and lines represent hypotheses and assumptions about behavior that lead to predictions and are subject to test and improvement.

Learning versus performance. In part because of its concern with the form of responding and lack of focus on associations, there is a tendency to view the behavior systems approach as having to do with performance rather than learning (see, e.g., Davey, 1989). It is true that learning in a behavior system is not defined precisely in terms of a particular set of procedures or an exact number of associations; however, a behavior system both suggests what forms learning may take and serves as a framework for defining learning and relating it to behavior. The general principles of learning require a similar framework for dealing with learning, but it is only implicit in the careful tuning of experimental procedures and apparatus. The traditional belief that learning can be neatly isolated from behavior speaks more to the historical determination of experimenters to separate learning from motivation and instinct than to the evolutionary and developmental history of the organism under study (Galef, 1988; Timberlake, 1990; Timberlake \& Silva, 1994).

Two points seem worth making. First, behavior reflects the ways in which learning is related to evolutionary selection pressures. To throw away systematic information contained in the form and patterning of responding is a mistake. In fact, the form of responding can be a better window on the nature of learning than can more traditional measures of frequency, amplitude, or rate. $\mathrm{Re}$ call that both the form and the orientation of rats' responding shifted as a function of different intervals between a ball bearing CS and a food US (Timberlake et al., 1982). Under short intervals the rat went to the food tray, under longer intervals to the ball bearing. It is not clear how to deal with this difference in behavior without some theoretical guidance. The decision of whether to measure a single response (approach to the bearing or approach to the food tray) or two responses (approach to the bearing and to the food tray) has critical implications for the conclusions drawn. 
Second, the traditional belief that learning can and must be separated from performance seems based in part on the assumption that learning in a pure and simplified form occurs at the neurophysiological level, if we could but measure it. To the contrary, as we know more about learning at a neurophysiological level, the more related it seems to be to the circumstances. The type of stimulus and response, the immediate history of neuronal spiking, the relative local concentrations of enzymes, the fit of event timing with ongoing neural firing patterns, and the stage of the day-night cycle all appear to affect and be incorporated in the learning (Kandel, Schwartz, \& Jessell, 1991). Thus, perhaps especially at the neural level, learning occurs and is expressed within a complex system.

Taking this lesson back to the level of overt behavior, it seems evident that the study of learning requires more attention to the processing, motor, and motivational aspects of the system within which it occurs. Understanding such a system would be improved by more careful consideration of the circumstances of learned behavior, including establishing the role of competition between and within modes for the final common pathway of expression (McFarland \& Sibley, 1975), clarifying how a CS may relate to more than one mode, and discovering whether the qualities of a CS that engage specific highly integrated modules are processed differently than its spatial-temporal relation to reward.

Precursors and contemporaries. Several reviewers were concerned that precursors and contemporaries of the behavior systems approach were not adequately credited. As pointed out elsewhere (Timberlake, 1983b; Timberlake \& Silva, 1994; Timberlake \& Silva, in press), I am delighted to acknowledge the debt of this approach to the ethologists-especially to Tinbergen.(1951), but also to Baerends (1988), Kruijt (1964), Lorenz (1981), and others. Though initially it was generated differently, the behavior systems approach can readily be seen as an extension of Tinbergen's hierarchical model that focuses more on learning and spends more effort separating the priming effects of motivation from the specific temporal and sequential organization of behavior (Timberlake \& Silva, in press). This approach also shares important assumptions and goals with a number of psychologists interested in combining laboratory and field techniques in the study of naturally occurring learning (Bolles, 1970; Davey, 1989; Garcia \& Garcia y Robertson, 1985; Hollis, 1990; Kamil, 1988; Shettleworth, 1993).

Finally, the behavior systems approach shares common ground with a number of laboratory approaches that emphasize the importance of a sequence of motivational states in Pavlovian conditioning (e.g., Konorski, 1967; Solomon \& Corbit, 1974; Wagner, 1981). Each of these approaches is valuable because it emphasizes phenomena not well accounted for in the traditional associative approach. The work of Konorski comes especially close to the behavior systems view in arguing that Pavlovian learning involves the conditioning of two mo- tivational states, a preparatory (drive) state and a consummatory state. The preparatory state is assumed to support the conditioning of diffuse excitatory preparatory responses at relatively long CS-US intervals, while the consummatory state supports the conditioning of precise focused responses at short CS--US intervals.

Although Konorski's (1967) view overlaps considerably with the present approach, there appear to be several differences worth exploring. One is that Konorski's approach does not separate the preparatory state into substates or modes, such as general search and focal search. As a result, there does not appear to be as strong a basis for predicting the different shapes of responding as a function of the CS-US interval. Another difference is that Konorski's view lacks the stimulus-response specificity provided by the perceptual-motor modules of a behavior system. His approach predicts only diffuse excitatory responses for the preparatory state and uses a variant of stimulus substitution to predict responses in the consummatory state. In the behavior systems approach, modules provide the basis for predicting the form of specific focused responses in the presence of particular stimuli. Perhaps most importantly, in the behavior systems' view specific modules and their responses can be engaged in preparatory as well as consummatory states. Thus, there should be instances of specific as well as diffuse responding in the preparatory state, depending on the stimulus conditions.

\section{The Perceived Adequacy of the Associative Account}

Given the data and arguments reviewed above and in the accompanying three symposium articles, it might be assumed that the behavior systems account is a worthwhile addition to the traditional associative approach. But this is by no means a universal view. As reviewers of these papers have pointed out, much of the data supporting the behavior systems account can be explained in a post hoc fashion by simple associative mechanisms. More complex behavior can be dealt with by combining more complex associative phenomena such as inhibition, latent inhibition, blocking, overshadowing, context conditioning, and configural learning. The neurophysiological data can be dealt with as the localized realization of associative connections. As for any remaining puzzles, it has been argued that it is no surprise that evolution and species-typical behavior have a contribution to behavior (Skinner, 1966).

The associative approach is a powerful and familiar set of concepts, laws, and procedures. It has served well for over 100 years, and there is life in it yet. It has been revised and added to extensively in the last 30 years and still makes quantitatively accurate predictions of learned performance. Why abandon it? More often than not, the conservatism of mainstream science in rejecting new alternatives is justifiable. Please notice, though, that the argument is not to abandon the associative approach in favor of an alternative view, but to embed associations in a more inclusive and specific framework. Associative mechanisms are not the problem. The difficulties are 
similar to those raised with the behavior systems approach: a lack of completeness and an element of idiosyncrasy in its predictions.

The associative approach is incomplete. It seems evident that the associative account is an incomplete guide to the broad sweep of behavior (Timberlake, in press). Experience in some form may affect every response. But Pavlovian and operant conditioning paradigms are not adequate explanations for all experience-based changes in behavior. Though the pressure to expand the associative approach to account for all behavior has been large, many important phenomena still do not readily fall out of a simple associative approach: motivational sequences, regulation, adaptation, preorganized perceptual-motor organization, and the course of development and evolution. An approach like behavior systems seems an important addition to help organize and summarize the myriad determinants of behavior (Timberlake, 1993a).

More importantly for our purposes here, the associative account also is an incomplete guide to laboratory learning. One major difficulty is the prediction of the form of the conditional response. In constrained Pavlovian paradigms, it was possible to argue that the form of the response was accounted for by stimulus substitution, the notion that the CS substituted for the US in eliciting unconditioned responding. However, strings of appetitive responses frequently do not resemble consummatory behavior, particularly in the case of long CS-US intervals and CSs that readily fit perceptual-motor organization concerned with searching for rather than consuming food.

Temporal conditioning paradigms (fixed-time intervals of food presentation) created similar problems for a stimulus substitution view. Interfood behavior frequently fails to resemble consummatory behavior (e.g., Matthews \& Lerer, 1987; Reberg, Innis, Mann, \& Eizenga, 1978). At one time, this complexity was attributed to superstitious operant conditioning (Skinner, 1948). Accidental pairings of periodic reward with a response generated a positive feedback loop between the probability of responding and the probability of reward. The first difficulty with this clever explanation was that, in longer interfood intervals, responses such as drinking or attacking a conspecific emerged following rather than preceding food (Falk, 1971; Staddon, 1977; Timberlake \& Lucas, 1991). The second difficulty was that behavior in short interfood intervals appeared too similar to be generated by accidental pairings. Staddon and Simmelhag (1971) reported that all their pigeons pecked and/or engaged in wall-directed responses. Timberlake and Lucas (1985) reported wall-directed behavior or ground foraging behavior, depending on the proximity of the feeder to a wall.

A second issue concerns the failure of the associative approach to account for the critical contribution of the experimenter's choice of apparatus, procedures, and species in making the approach work. Most scientists admire simplicity in theories. The more economical and aesthetically pleasing a law, the more inclined we are to accept it and assume its accuracy. For researchers who admire the apparent clarity and simplicity of the general laws of association, consider what the experimenter must add in the way of the tuning of the apparatus and procedures to allow a test of these laws. To focus this problem further, suppose an independent testing body hired a young physicist to test the general laws of learning. Given enough time and some talent for watching animals, the physicist could probably produce examples of learning laws. But he/she would have done so by rediscovering the relevant procedures, apparatus, and knowledge of the species.

Admittedly, all sciences employ a logic-in-use that is not contained in their theories. The question is whether what is left to the procedures and apparatus is systematic and important enough to be represented in the theoretical approach. I think the answer for learning is "yes." That the predominate arbitrary instrumental responses in learning (maze running and leverpressing in rats, keylight pecking in pigeons) emerge under simple exposure or CS-US pairings implies a level of organization that must be considered systematically.

The associative approach is idiosyncratic. The history of learning research is filled with contradictory theories of the determinants of learning, contradictory interpretations of the same data, and remarkably different critical tests. Individual laboratories show marked differences in the specifics of their procedures for deprivation, transportation, and adaptation of the animals to the apparatus. Accounts of extinction continue to show unique variations among individual researchers.

If such arguments for idiosyncrasy are not sufficiently convincing, consider asking a group of learning researchers to predict the outcome of a simple but slightly out-of-theordinary manipulation, such as the relative amount of forward and backward conditioning with different CS-US intervals. The problem is not just the pragmatic one of trying to agree on a common measure of conditioning, but a conceptual one as well. Which of the myriad concepts in the associative arsenal should be invoked to make the predictions? Should we invoke one set of concepts to explain the results of forward conditioning and another to explain backward conditioning? How can we hedge our bets about the order of conditioning? Because Fran Silva and I have asked this question of several researchers, I can report that these data show high individual variance.

It might be argued that backward conditioning is an unfairly complex phenomenon, but why? The circumstances of backward conditioning appear to occur with some regularity in freely behaving animals. But the concern may be moot, because I have good reason to expect similar variability in responses if we had asked for predictions on the results of a serial conditioning procedure. I believe that surprisingly idiosyncratic explanations of many learning phenomena occur in part because there actually is no single associative account that adequately covers the field of learning. Instead, there are combinations of concepts, manipulations, and measures that work together in particular circumstances.

In sum, conceiving of learning as limited to particular paradigms, and of behavior as constructed primarily 
from simple learned associations, has produced an incomplete and perhaps surprisingly idiosyncratic account of Pavlovian conditioning. It focuses on the structure provided by the experimenter's manipulations instead of on the functional behavior systems of animals and how they adjust to constraints. The general success of models of learning based on connections between simple elements has been bought at the cost of some uncertainty as to their generalizability to situations that have not been tuned by experimenters to isolate the determinants and effects of interest. Although the isolation of phenomena for the purposes of study is a powerful technique dating back at least to the study of spinal reflexes (Sherrington, 1906), it is ultimately an incomplete venture that must be embedded within a larger framework to account for behavior (Fearing, 1930; Sherrington, 1906; Timberlake, 1993b).

\section{CONCLUSIONS}

There are many positive aspects of both associative and behavior system approaches to Pavlovian conditioning. The elimination of either one would leave out part of the known characteristics of learned behavior. The associative account has focused attention on variables such as the frequency and intensity of the US, the CS-US interval and contingency relation, the context, and multiple and configural aspects of stimuli. Data supporting the importance of most of these variables has been accumulating during most of this century. Adaptiveevolutionary accounts of learning have been around equally as long, but the specific relation of the behavior systems approach to laboratory learning has been explored systematically only briefly. During this time the behavior systems account has successfully predicted the form and ease of conditioning as a function of a variety of CSs and USs, as well as effects of the temporal and spatial proximity of the CS and US.

There is a strong tendency to focus exclusively on the associative approach because it is familiar and because of the apparent power and simplicity of its general laws. There is little question that the accumulated evidence for associations is impressive and important. However, as argued above, the simplicity of associative laws is misleading. Extensive tuning and experience are necessary to apply them. Further, in practice the apparent coherence of the associative approach has begun to fragment (probably necessarily) into subareas concerned with specific types of problem in specific subsets of procedure.

The associative approach to Pavlovian conditioning is relatively weak in areas where the behavior systems approach has strengths. The latter deals readily with prediction of response form, the relation of stimulus filtering to learning, and constraints on learning. On the associative side, stimulus substitution makes relatively specific predictions about the form of responding (though see Hearst \& Jenkins, 1974), but these are frequently wrong, especially when applied to relatively long CS-US intervals (Fanselow, 1989; Timberlake,
1986). The concepts of stimulus salience and configural conditioning can be used quite cleverly, but unless they can be tied successfully to a single physical dimension, they are difficult to pin down. Finally, the treatment of ecological constraints on learning has been particularly unsatisfying. Obvious differences in conditioning have been attributed to the post hoc labels of "constraints" and "preparedness," a circular and ultimately not very interesting explanation.

The behavior systems approach can also contribute an enduring framework for the study of learned behavior. The focus of associative models on manipulations and simple associations has meant that experimenters sometimes have tested theories to the detriment of finding out more about their subjects as functioning systems. Thus, when a particular theory is wrong, the theory and the data collected in testing it are left behind. In contrast, a behavior system can be added to and corrected by further experimental results and observations. Rather than only proving or disproving a hypothesis, research can contribute to and be affected by systematized knowledge about an organism's characteristics. Thus at the end of a well-designed experiment, we should have an answer to our experimental questions along with an improved version of the particular system involved and how it functions.

A primary goal of the study of laboratory learning is the documentation and explanation of the many specific ways in which the functioning of a system can be modified. All forms of learning are a result of a combination of the system and the constraints of the environment. Learning results from evolved tendencies to increase the fit of a specific animal with a particular environment. Some early researchers focused on the specific role of learning in survival, especially in development (see Galef, 1990; Timberlake, 1983b; Timberlake \& Silva, 1994). But the majority of this century has been dominated by a concern with abstract general laws of learning. The recent interest in animal cognition has begun to restore concerns with species-typical processing and integration (Brodbeck, 1994; Clayton \& Krebs, 1994; Shettleworth, 1993). By explicitly embedding such work within the larger framework of a behavior system and specific mechanisms of learning, we may move the study of learning closer to the study of behavior and its attendant evolutionary and neurophysiological bases.

\section{REFERENCES}

Akins, C. A., Domjan, M., \& Gutierrez, G. (1994). The topography of sexually conditioned behavior in male Japanese quail (Coturnix japonica) depends on the CS-US interval. Journal of Experimental Psychology: Animal Behavior Processes, 21, 199-209.

BAERENDS, G. P. (1976). On drive, conflict, and instinct, and the functional organization of behavior. In M. A. Corner \& D. F. Swaab (Eds.), Perspectives in brain research: Proceedings (Progress in Brain Research, Vol. 45, pp. 427-447). Amsterdam: North-Holland.

BaEREnds, G. P. (1988). Ethology. In R. C. Atkinson, R. J. Herrnstein, G. Lindzey, \& R. D. Luce (Eds.), Stevens' Handbook of experimental psychology: Vol. 2. Learning and cognition (2nd ed., pp. 765830). New York: Wiley. 
BarnetT, S. A. (1975). The rat: A study in behavior. Chicago: University of Chicago Press.

BOLLES, R. C. (1970). Species-specific defense reactions and avoidance learning. Psychological Review, 77, 32-48.

Bolles, R. C., \& Woons, P. J. (1964). The ontogeny of behaviour in the albino rat. Animal Behaviour, 12, 427-441.

BorING, E. G. (1968). The influence of evolutionary theory upon American psychological thought. In S. Persons (Ed.), Evolutionary thought in America (pp. 268-298). New Haven, CT: Yale University Press.

Brant, D. H., \& Kavanau, J. L. (1965). "Unrewarded" exploration and learning of complex mazes by wild and domestic mice. Nature, 204, 267-269.

Breland, K., \& Breland, M. (1961). The misbehavior of organisms. American Psychologist, 16, 681-684

BroDbEck, D. R. (1994). Memory for spatial and local cues: A comparison of a storing and a nonstoring species. Animal Learning \& Behavior, 22, 119-133.

CALhoun, J. B. (1962). The ecology and sociology of the Norway rat (Publication No. 1008). Bethesda, MD: U.S. Department of Health, Education, and Welfare.

Clayton, N. S., \& KREBS, J. R. (1994). One-trial associative memory: Comparison of food-storing and nonstoring species of birds. Animal Learning \& Behavior, 22, 366-372.

DASHIELL, J. F. (1937). Fundamentals of objective psychology. Boston, MA: Houghton-Mifflin.

DAveY, G. (1989). Ecological learning theory. New York: Routledge DewsBury, D. A. (1994). The comparative psychology of Paul Schiller. Psychological Record, 44, 326-350.

DOMJAN, M. (1994). Formulation of a behavior system for sexual conditioning. Psychonomic Bulletin \& Review, 1, 421-428.

EWER, R. F. (1971). The biology and behavior of a free-living population of black rats (Rattus rattus). Animal Behavior Monographs, $4(3)$.

FALK, J. L. (1971). The nature and determinants of adjunctive behavior. Physiology \& Behavior, 6, 577-588.

FANSELOW, M. S. (1989). The adaptive function of conditioned defensive behavior: An ecological approach to Pavlovian stimulus substitution theory. In R. J. Blanchard, P. F. Brain, D. C. Blanchard, \& S. Parmigiani (Eds.), Ethoexperimental approaches to the study of behavior (pp. 151-166). Boston: Kluwer Academic.

FANSELOW, M. S. (1991). The midgray periaqueductal gray as a coordinator of action in response to fear and anxiety. In A. Depaulis \& R. Bandler (Eds.), The midbrain periaqueductal grey matter: Functional, anatomical and immunohistochemical organization (pp. 151173). New York: Plenum.

FANSELOW, M. S. (1994). Neural organization of the defensive behavior system responsible for fear. Psychonomic Bulletin \& Review, 1 , 429-438.

Fanselow, M. S., \& LeSTER, L. S. (1988). A functional behavioristic approach to aversively motivated behavior: Predatory imminence as a determinant of the topography of defensive behavior. In R. C. Bolles \& M. D. Beecher (Eds.), Evolution and learning (pp. 185212). Hillsdale, NJ: Erlbaum.

FEARING, F. (1930). Reflex action. Baltimore: Williams \& Wilkins.

GALEF, B. G. (1988). Evolution and learning before Thorndike: A forgotten epoch in the history of behavioral research. In R. C. Bolles \& M. D. Beecher (Eds.), Evolution and learning (pp. 39-58). Hillsdale, NJ: Erlbaum.

GaLEF, B. G. (1990). An adaptationist perspective on social learning, social feeding, and social foraging in Norway rats. In D. A. Dewsbury (Ed.), Contemporary issues in comparative psychology (pp. 55-79). Sunderland, MA: Sinauer.

GaRCIA, J., \& GARCIA Y ROBERTSON, R. (1985). Evolution of learning mechanisms. In B. L. Hammonds (Ed.), Psychology and learning: The master lecture series (Vol. 4, pp. 187-243). Washington, DC: American Psychological Association.

GARDNER, R. A., \& GARDNER, B. T. (1988). Feedforward versus feedbackward: An ethological alternative to the law of effect. Behavioral \& Brain Sciences, 11, 429-447.

Gormezano, I., \& KehOE, E. J. (1975). Classical conditioning: Some methodological-conceptual issues. In W. K. Estes (Ed.), Handbook of learning and cognitive processes: Vol. 2. Conditioning and behavior theory (pp. 143-179). Hillsdale, NJ: Erlbaum.

GotTLieb, G. (1976). Conceptions of prenatal development: Behavioral embryology. Psychological Review, 83, 215-234.

Hearst, E. (1988). Fundamentals of learning and conditioning. In R. C. Atkinson, R. J. Herrnstein, G. Lindzey, \& R. D. Luce (Eds.), Stevens' Handbook of experimental psychology: Vol. 2. Learning and cognition (2nd ed., pp. 3-109). New York: Wiley.

Hearst, E., \& Jenkins, H. M. (1974). Sign-tracking: The stimulusreinforcer relation and directed action. Austin, TX: Psychonomic Society.

HILGARD, E. R., \& MARQUIS, D. G. (1940). Conditioning and learning. New York: Appleton-Century-Crofts.

Hogan, J. A. (1984). Pecking and feeding in chicks. Learning \& Motivation, 15, 360-376.

HoGaN, J. A. (1989). Cause and function in the development of behavior systems. In E. M. Blass (Ed.), Handbook of behavioral neurobiology (Vol. 9, pp. 63-106).

HoGAN, J. A. (1994). Structure and development of behavior systems. Psychonomic Bulletin \& Review, 1, 439-450.

HolLAND, P. C. (1980). CS-US interval as a determinant of the form of Pavlovian appetitive conditioned responses. Journal of Experimental Psychology: Animal Behavior Processes, 6, 155-174.

HollaNd, P. C. (1984). Origins of behavior in Pavlovian conditioning. In G. H. Bower (Ed.), The psychology of learning and motivation (Vol. 18, pp. 129-174). Orlando, FL: Academic Press.

HoLlis, K. L. (1982). Pavlovian conditioning of signal-centered action patterns and autonomic behavior: A biological analysis of function. In J. S. Rosenblatt, R. A. Hinde, C. Beer, \& M. C. Busnel (Eds.), Advances in the study of behavior (Vol. 12, pp. 1-64). New York: Academic Press.

HoLLIS, K. L. (1990). The role of Pavlovian conditioning in territorial aggression and reproduction. In D. A. Dewsbury (Ed.), Contemporary issues in comparative psychology (pp. 197-219). Sunderland, MA: Sinauer.

JENKINS, H. M. (1979). Animal learning and behavior theory. In E. Hearst (Ed.), The first century of experimental psychology (pp. 177-228)

JoHNSTON, T. D. (1981). Contrasting approaches to a theory of learning. Behavioral \& Brain Sciences, 4, 125-139.

KAMIL, A. C. (1988). A synthetic approach to animal intelligence. In D. W. Leger (Ed.), Nebraska Symposium on Motivation, 1987: Comparative perspectives in modern psychology (pp. 257-308). Lincoln: University of Nebraska Press.

Kamil, A. C., \& Mauldin, J. E. (1988). A comparative-ecological approach to the study of learning. In R. C. Bolles \& M. D. Beecher (Eds.), Evolution and learning (pp.117-133). Hillsdale, NJ: Erlbaum.

Kandel, E. R., Schwartz, J. H., \& Jessell, T. M. (1991). Principles of neural science. New York: Elsevier.

KEHOE, E. J. (1982). Conditioning with serial compound stimuli: Theoretical and empirical issues. Experimental Animal Behaviour, 1, 30-65.

Kumble, G. A. (1961). Hilgard and Marquis' conditioning and learning. New York: Academic Press.

KONORSKI, J. (1967). Integrative activity of the brain. Chicago: University of Chicago Press.

KRUIJT, J. P. (1964). Ontogeny of social behaviour in Burmese red jungle fowl (Gallus gallus spadiceus). Behaviour (Suppl. 12), 1-201.

LORENZ, K. (1981). The foundations of ethology. New York: SpringerVerlag.

MaCKINTOSH, N. J. (1974). The psychology of animal learning. New York: Academic Press.

Maier, N. R. F., \& Schneirla, T. C. (1935). Principles of animal psychology. New York: McGraw-Hill.

MATThEWS, T. J., \& LERER, B. E. (1987). Behavior patterns in pigeons during autoshaping with an incremental conditioned stimulus. Animal Learning \& Behavior, 15, 69-75.

MAZUR, J. E. (1990). Learning and behavior (2nd ed.). Englewood Cliffs, NJ: Prentice-Hall. 
McFarland, D. J., \& Sibley, R. M. (1975). The behavioural final common path. Philosophical Transactions of the Royal Society: Series $B, 270,265-293$.

MiLleR, R. R., \& MATZEL, L. D. (1988). The comparator hypothesis: A response rule for the expression of associations. In G. H. Bower (Ed.), The psychology of learning and motivation (pp. 51-92). Orlando, FL: Academic Press.

Moore, B. R., \& Stuttard, S. (1979). Dr. Guthrie and Felis domesticus or: Tripping over the cat. Science, 205, 1031-1033.

MORRIS, D. (1958). The reproductive behavior of the ten-spined stickleback (Pygosteus pungitius L.). Behaviour (Suppl. 6), 1-154.

Notтевонм, F. (1972). The origins of vocal learning. American Naturalist, 106, 116-140

Pavlov, 1. P. (1927). Conditioned reflexes (G. V. Anrep, Ed. and Trans.) London: Oxford University Press.

Pear, J. J., \& Eldridge, G. D. (1984). The operant-respondent distinction: Future directions. Journal of the Experimental Analysis of Behavior, 42, 453-467.

Platt, J. (1964). Strong inference. Science, 146, 347-353.

Reberg, D., InNis, N. K., Mann, B., \& Eizenga, C. (1978). "Superstitious" behavior resulting from periodic response-independent presentations of food or water. Animal Behaviour, 26, 506-519.

ResCorla, R. A., \& Holland, P. C. (1982). Behavioral studies of associative learning in animals. Annual Review of Psychology, 33, 265-308.

Rozin, P., \& Schull, J. (1988). The adaptive-evolutionary point of view in experimental psychology. In R. C. Atkinson, R. J. Herrnstein, G. Lindzey, \& R D. Luce (Eds.), Stevens's handbook of experimental psychology: Vol. 2. Learning and cognition (2nd ed., pp. 503-546). New York: Wiley.

SCHNEIDERman, N. (1972). Response system divergences in aversive classical conditioning. In A. H. Black \& W. F. Prokasy (Eds.), Classical conditioning II: Current research and theory (pp. 341-376) New York: Appleton-Century-Crofts.

Scotr, J. P. (1958). Animal behavior. Chicago: University of Chicago Press.

SHERRINGTON, C. S. (1906). The integrative action of the nervous system. New Haven, CT: Yale University Press.

SHETTLEWORTH, S. J. (1993). Where is the comparison in comparative cognition? Alternative research programs. Psychological Science, 4, 179-184.

SKINNER, B. F. (1938). The behavior of organisms: An experimental analysis. New York: Appleton-Century-Crofts.

SKINNER, B. F. (1948). "Superstition" in the pigeon. Journal of Experimental Psychology, 38, 168-172.

SkinNer, B. F. (1956). A case history in the scientific method. American Psychologist, 11, 221-233.

SkinNer, B. F. (1966). The phylogeny and ontogeny of behavior. Science, 153, 1205-1213.

SOlomon, R. L., \& CoRBIT, J. D. (1974). An opponent-process theory of motivation: I. Temporal dynamics of affect. Psychological Review, 81, 119-145.

StadDON, J. E. R. (1977). Schedule-induced behavior. In W. K. Honig \& J. E. R. Staddon (Eds.), Handbook of operant behavior (pp. 125152). Englewood Cliffs, NJ: Prentice-Hall.

Staddon, J. E. R., \& Simmelhag, V. L. (1971). The "superstition" experiment: A reexamination of its implications for the principles of adaptive behavior. Psychological Review, 78, 3-43.

STEININGER, F. von (1950). Beiträge zur Soziologie und sonstigen Biologie der Wanderatte. Zeitschrift für Tierpsychologie, 7, 356-379.

STOKES, P. D., \& BALSAM, P. D. (1991). Effects of reinforcing preselected approximations to the topography of the rat's bar press. Journal of the Experimental Analysis of Behavior, 55, 129-196.

TELLE, J. J. (1966). Beiträge zur Kenntnis der Verhaltensweise von Ratten, vergleichend dargestellt bei, Rattus norvegicus und Rattus rattus. Zeitschrift für Angewandte Zoologie, 53, 129-196.

Thorndike, E. L. (1911), Animal intelligence. New York: Macmillan.
TimberlaKe, W. (1983a). Appetitive structure and straight alley running. In R. Mellgren (Ed.), Animal cognition and behavior (pp. 165 222). Amsterdam: North-Holland.

TimberLaKE, W. (1983b). The functional organization of appetitive behavior: Behavior systems and learning. In M. D. Zeiler \& P. Harzem (Eds.), Advances in the analysis of behavior: Vol. 3. Biological factors in learning (pp. 177-221). New York: Wiley.

Timberlake, W. (1986). Unpredicted food produces a mode of behavior that affects rats' subsequent reactions to a conditioned stimulus: A behavior-system approach to "context blocking." Animal Learning \& Behavior, 14, 276-286.

TimberLaKe, W. (1990). Natural learning in laboratory paradigms. In D. A. Dewsbury (Ed.), Contemporary issues in comparative psychology (pp. 31-54). Sunderland, MA: Sinauer.

TIMBERLAKE, W. (1993a). Animal behavior: A continuing synthesis Annual Review of Psychology, 44, 675-708.

TimBerLaKe, W. (1993b). Behavior systems and reinforcement: An integrative approach. Journal of the Experimental Analysis of Behavior, 60, 105-128.

TiMBERLAKE, W. (in press). Reconceptualizing reinforcement: A causal system approach to reinforcement and behavior change. In W. O'Donohue \& L. Krasner (Eds.), Theories in behavior therapy. Washington, DC: APA Books.

Timberlake, W., \& Grant, D. L. (1975). Autoshaping in rats to the presentation of another rat predicting food. Science, 190, 690-692.

Timberlake, W., \& LuCas, G. A. (1985). The basis of superstitious behavior: Response contingency, stimulus substitution, or appetitive behavior? Journal of the Experimental Analysis of Behavior, 44 279-299.

TimberLaKe, W., \& Lucas, G. A. (1989). Behavior systems and learning: From misbehavior to general principles. In S. B. Klein \& R. R. Mower (Eds.), Contemporary learning theories: Instrumental conditioning theory and the impact of biological constraints on learning (pp. 237-275). Hillsdale, NJ: Erlbaum.

Timberlake, W., \& LuCas, G. A. (1991). Periodic water, interwater interval, and adjunctive behavior in a 24-hour multiresponse environment. Animal Learning \& Behavior, 19, 369-380.

Timberlake, W., \& Silva, F. J. (1994). Observation of behavior, inference of function, and the study of learning. Psychonomic Bulletin \& Review, 1, 73-88.

Timberlake, W., \& Silva, K. M. (in press). Appetitive behavior in ethology, psychology, and behavior systems. In N. Thompson (Ed.), Perspectives in ethology. New York: Plenum.

Timberlake, W., Wahl, G., \& King, D. (1982). Stimulus and response contingencies in the misbehavior of rats. Journal of Experimental Psychology: Animal Behavior Processes, 8, 62-85.

Timberlake, W., \& Washburne, D. L. (1989). Feeding ecology and laboratory predatory behavior toward live and artificial moving prey in seven rodent species. Animal Learning \& Behavior, 17, 2-10.

Timberlake, W., \& WhiTe, W. (1990). Winning isn't everything: Rats need only food deprivation not food reward to traverse a radial arm maze efficiently. Learning \& Motivation, 21, 153-163.

TinBERGEN, N. (1951). The study of instinct. Oxford: Oxford University Press, Clarendon Press.

WAGNER, A. R. (1981). A model of automatic memory processing in animal behavior. In N. E. Spear \& R. R. Miller (Eds.), Information processing in animals: Memory mechanisms (pp. 5-47). Hillsdale, NJ: Erlbaum.

WARDEn, C. J., Jenkins, T. N., \& Warner, L. H. (1935). Comparative psychology: Principles and methods (Vol. 1). New York: Ronald Press.

Wasserman, E. A. (1993). Comparative cognition: Beginning the second century of the study of animal inteliigence. Psychological Bulletin, 113, 211-228

(Manuscript received November 19, 1993; revision accepted for publication August 8,1994 .) 